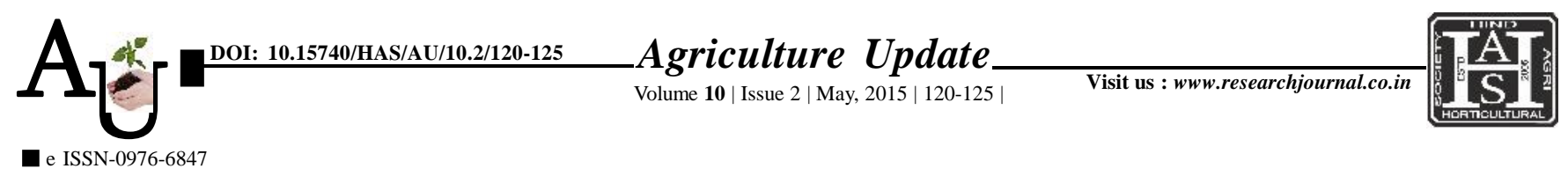

\title{
Research Article: Knowledge and adoption of recommended chilli production technology by the farmers of Raipur district
}

\section{SUSHIL KUMAR VERMA*, D.P. RAI AND LEKH RAM VERMA}

Article Chronicle :

Received :

04.02.2015;

Revised :

15.03.2015;

Accepted :

01.04 .2015

KeY Words :

Chilli production,

Knowledge, Adoption

How to cite this article : Verma, Sushil Kumar, Rai, D.P. and Verma, Lekh Ram (2015). Knowledge and adoption
of recommended chilli production technology by the farmers of Raipur district. Agric. Update, 10(2): 120-125.

SUMMARY : The investigation was carried out in Dharsiwa block, Raipur district of Chhattisgarh state in 2010-2011, to assess the level of knowledge and extent of adoption of recommended practices of chilli production technology. From the selected block, twelve villages and from each village ten chilli growing farmers who were growing chilli for at least last two years were selected. Data were recorded through interview schedule and analyzed to use appropriate statistical methods. The study revealed that the maximum (38.33\%) respondents had medium level of overall knowledge about chilli production technology. Whereas practice wise majority $(55.00 \%)$ of the respondents had high level of knowledge regarding recommended field preparation, majority $(52.50 \%)$ of the respondents had medium level of knowledge regarding irrigation management, and majority (50.83\%) of the respondents had low level of knowledge regarding recommended weed management, while 43.33 per cent respondents had low extent of adoption about recommended chilli production technology. So far as practice wise extent of adoption is concerned, maximum (32.50\%) respondents had high extent of adoption regarding recommended field preparation, majority $(50.00 \%)$ of the respondents had medium extent of adoption regarding irrigation management and majority $(59.17 \%)$ of the respondents had low level of extent of adoption regarding recommended weed management practices.
Author for correspondence :

\section{SUSHIL KUMAR}

\section{VERMA}

Agricultural Technology Management Agencies, KABIRDHAM (C.G.) INDIA Email: sushilverma4585 @ gmail.com

See end of the article for authors' affiliations 